\title{
Radiologic Diagnosis of Barrett's Esophagus: Critical Analysis of 65 Cases
}

\author{
Farooq P. Agha \\ Department of Radiology, University of Michigan Hospitals, Ann Arbor, Michigan, USA
}

\begin{abstract}
A recent increase in the number of Barrett's esophagis being diagnosed is probably directly related to a proportional increase in endoscopic biopsies of the esophagus and awareness of premalignant potential of Barrett's mucosa. While the endoscopist can detect Barrett's mucosa with fair degree of accuracy, the radiologic diagnosis of Barrett's esophagus still remains a diagnostic challenge despite several well established radiologic features. We reviewed 65 patients with pathologically proven Barrett's esophagus and found a wide spectrum of radiologic features. These include hiatus hernia in 49 , gastroesophageal reflux in 38 , strictures in 32 , esophagitis in 20, and characteristic Barrett's ulcer in 12 . In addition ascending or migrating strictures were found in 10 , mucosal pattern simulating areae gastricae in 5 , cricopharyngeal dysfunction in 4, and fixed spiral folds in 3 patients. This constellation of radiologic features, some of which have not been previously emphasized, should further assist radiologists in suggesting the diagnosis of Barrett's esophagus.
\end{abstract}

Key words: Barrett's esophagus, radiologic diagnosis - Esophagus, inflammation.

Since Barrett's original description of columnar lined lower esophagus [1], a great deal more has been learned about this condition. A growing interest on the part of clinicians, radiologists, and pathologists has deluged the literature with this fascinating entity [2-18]. While Barrett's esophagus occurs in only $4 \%$ of patients with symptomatic gastroesophageal reflux (GER), its clinical evolu-

Address reprint requests to: Farooq P. Agha, M.D., Department of Radiology, Box 13, University Hospital, 1405 East Ann Street, Ann Arbor, MI 48109, USA tion has attracted much attention [19, 20]. Although initially it was believed to be a congenital phenomenon, it is now generally believed that Barrett's esophagus results from chronic GER with squamous epithelial destruction and eventual replacement by a unique form of columnar epithelium. While there is bimodal age distribution that suggests some uncommon congenital influence, the vast majority of patients have acquired columnar lined esophagus from chronic GER. Barrett's esophagus is being diagnosed with greater frequency in most institutions. We have experienced similar increased incidence of Barrett's esophagus at our institution during the past 6 years. Despite several well established diagnostic criteria described in the literature $[5,21-24]$, the radiologic diagnosis of Barrett's esophagus remains a challenge. The classic radiologic features of Barrett's esophagus consist of a mid or high esophageal stricture and/or an ulcer associated with hiatus hernia and GER. Others, however, have found that a majority of their cases did not fit the typical description and that strictures were more commonly found in the distal esophagus $[25,26]$. Recently a reticular pattern of the mucosa on doublecontrast esophagram was described. The authors noticed that this fine lacelike pattern distal to the stricture was present in about $30 \%$ ( 7 of 23 patients) of their patients [27]. Pathologically this pattern corresponded to the villous metaplasia of the specialized columnar epithelium. Despite all these diagnostic criteria Barrett's esophagus still remains a difficult radiologic diagnosis and often requires histopathologic verification.

To understand better the pathogenetic basis of its radiologic features we have studied 65 cases of pathologically proven Barrett's esophagus and report the critical analysis of radiographic features based upon this study. 


\section{Materials and Methods}

The medical records and radiologic studies of 65 patients with Barrett's esophagus seen at the University of Michigan Hospitals between January, 1977, and December, 1983, were reviewed retrospectively. All cases included in this study were histopathologically proven Barrett's esophagus without any evidence of adenocarcinoma. There were 29 women and 36 men ranging in age from 20 to 88 years, with a mean age of 56.8 years. The diagnosis of Barrett's esophagus was made by histopathologic examination of endoscopic biopsy specimens in all patients. Ten of those patients eventually underwent esophagectomy for refractory strictures and recurrent ulcerations. The histologic criteria for diagnosis of Barrett's esophagus used were those described by Paull and Trier [28]. Two patients had associated Zollinger-Ellison syndrome, 2 patients had scleroderma, 1 patient had multiple endocrine adenomatosis type I, and 1 patient had achalasia treated previously with Heller's myotomy. Twelve patients had previously been treated with antireflux operation, which failed to control the GER. Double-contrast esophagrams were available in 42 patients and single-contrast esophagrams in 23 patients. Serial (3-5) esophagrams were available in 48 patients.

\section{Results}

Dysphagia occurred as a presenting symptom in 50 of 65 patients. Dysphagia was of less than 6 months' duration in 35 patients and chronic lowgrade dysphagia of several years' duration was noted in 30 patients. The second most important symptom complex was heartburn and regurgitation in 45 of 65 patients. Only heartburn was present in 36 and regurgitation in 24 patients. In $80 \%$ of patients with GER the symptoms had been present for 5 years or longer. Eight patients presented with

Table 1. Radiographic features of Barrett's esophagus in 65 patients

\begin{tabular}{lll}
\hline Findings & $\begin{array}{l}\text { No. of } \\
\text { patients }\end{array}$ & $\%$ \\
\hline Hiatus hernia & 49 & 75 \\
Gastroesophageal reflux & 38 & 58 \\
Strictures & 32 & 49 \\
$\quad$ upper (6) & & \\
$\quad$ middle (9) & & \\
Ascending strictures & 10 & 15.4 \\
Esophagitis & 20 & 30 \\
Barrett's ulcer & 12 & 19 \\
Areae gastricae/ & & $12.5^{\mathrm{a}}$ \\
reticular esophageal mucosa & 5 & $7^{\mathrm{b}}$ \\
Fixed spiral folds & 3 & 6 \\
Cricopharyngeal dysfunction & 4 & \\
\hline
\end{tabular}

a Five of 42 patients who had double-contrast studies.

b Three of 42 patients who had double-contrast studies. hematemesis and/or melena, 5 with significant weight loss, and 3 with iron-deficiency anemia.

The radiologic features consisted of hiatus hernia (49 patients), gastroesophageal reflux (38), strictures (32) (upper in 6, middle in 9, lower in 17), esophagitis (20), Barrett's ulcer (12), reticular pattern of the mucosa or areae gastricae in the esophagus (5), cricopharyngeal dysfunction (4), and fixed spiral folds (3). These findings are summarized in Table 1.

\section{Discussion}

Patients with Barrett's esophagus usually have a 5-year or longer history of GER. However, Bremner [11] in his experimental dog model showed that $4 \mathrm{~cm}$ of columnar replacement epithelium developed after 2 years of GER. The incidence of Barrett's esophagus ranged from 4 to $10 \%$ among cases of symptomatic reflux esophagitis in reported series $[13,19,20]$. The results of this study show a wider spectrum of radiologic findings and some of those features have not been previously stressed adequately.

\section{Ascending or Migrating Strictures}

"A sign of Barrett's esophagus," the cyclic ulceration and healing leads to scarring and progressive stricture formation. The strictures may be found in any part of the esophagus. The previous literature stressed a mid or high stricture, in contrast to the current literature, which emphasizes a prevalence of lower esophageal stricture. The stricture in Barrett's esophagus marks the squamocolumnar junction. Progressive upward extension of squamocolumnar junction has been well documented previously $[6,14,29]$. Endo et al. have reported upward migration of squamocolumnar junction of $13 \mathrm{~cm}$ over a 5-year period in 1 case of Barrett's esophagus [29]. Goldman and Beckman reported a 66-year-old man with a 7-year follow up, who demonstrated a gradual ascent of his esophageal strictured area and mucosal replacement of squamous epithelium by columnar epithelium below the ascending stricture [14]. The Barrett's stricture is usually short, tight, and, occasionally, long. The lumen is eccentrically narrowed in contrast to conventional peptic stricture, which causes a smooth, symmetrical, and circumferential narrowing of the lumen. Asymmetrical narrowing of lumen in Barrett's esophagus is related to healing of the Barrett's ulcer. The ascending strictures can be best detected on serial esophagograms. Ascending strictures in Barrett's esophagus have not been stressed 

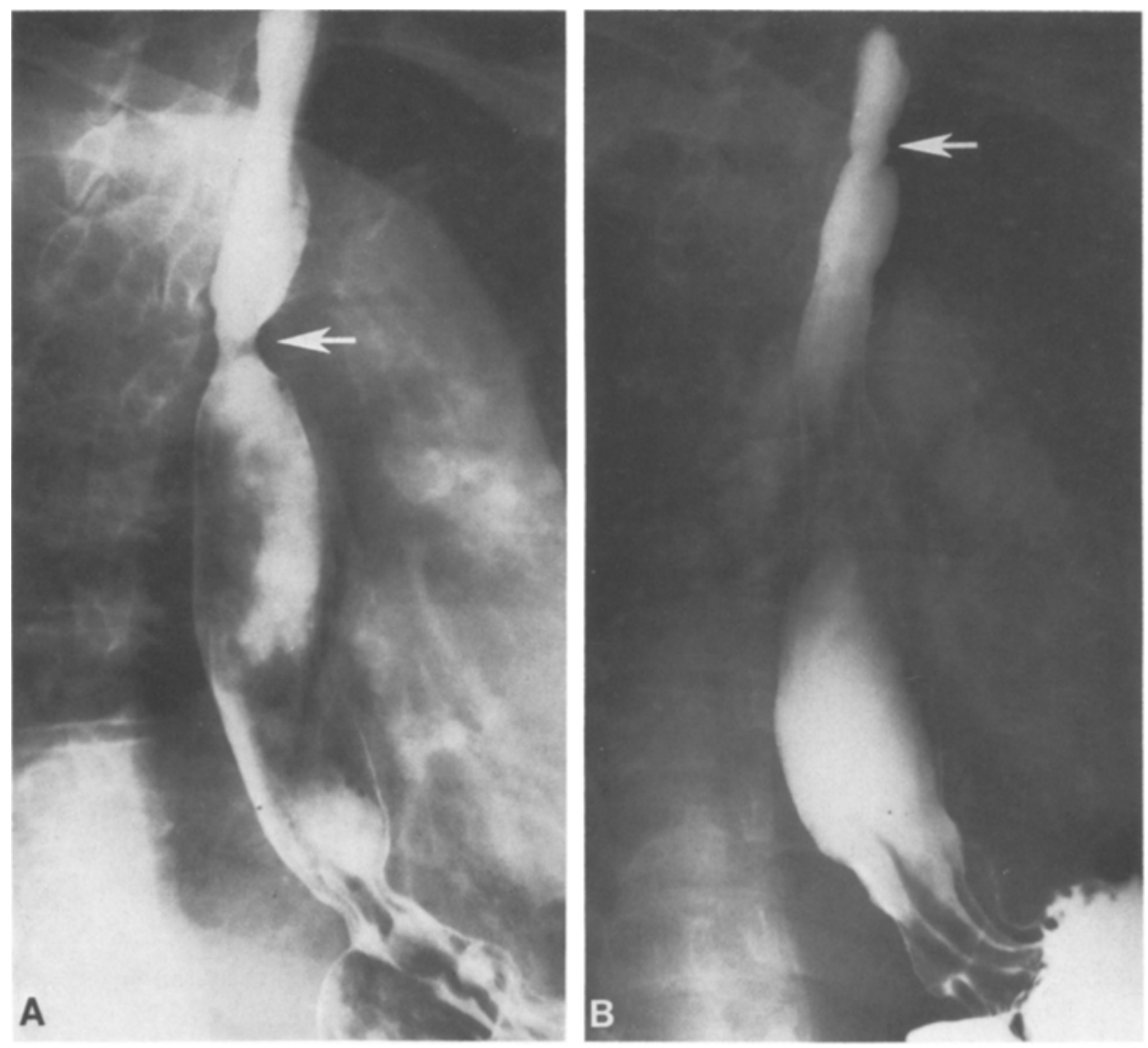

Fig. 1. Ascending stricture in Barrett's esophagus.

A Esophagogram shows a midesophageal stricture (arrow) in 1977.

B Two years later there is evidence for $4 \mathrm{~cm}$ proximal migration of the stricture (arrow).

previously and constitute a specific sign of Barrett's esophagus. This is directly related to the ascent of squamocolumnar epithelial junction as the damaged squamous epithelium is being replaced by columnar epithelium. Ten patients $(15.4 \%)$ in this series demonstrated ascending strictures at serial esophagograms (Fig. 1).

\section{Areae Gastricae in the Esophagus}

This reticular pattern of mucosa has been recently described in Barrett's esophagus by Levine et al. [27]. These authors noted this pattern on doublecontrast studies in $30 \%$ of their patients ( 7 of 23 patients) and demonstrated that pathologically this pattern corresponded to villous metaplasia of specialized columnar epithelium. Since then others have stated that it is found in $10-15 \%$ of cases and is a nonspecific finding (D. Gelfand, personal communication). We evaluated our material for this pattern and, to avoid interobserver variations, we equated this pattern with the areae gastricae seen in the stomach on double-contrast studies. Thus an esophagram showing areae gastricae pattern of the esophageal mucosa was considered pos- itive for reticular pattern. Five of 42 patients who underwent double-contrast studies showed this pattern (12.5\%) (Fig. 2). This is a valuable sign whenever positive and should be sought in cases of suspected Barrett's esophagus; however, this pattern has been seen in patients with squamous cell carcinoma and monilial and viral esophagitis, as well as superficial spreading carcinoma [27].

\section{Barrett's Ulcer}

The term Barrett's ulcer was initially coined by Allison and Johnstone [3]. It represents a specific chronic peptic ulcer situated in the columnar lined segment. Some Barrett's ulcers develop in the squamocolumnar transitional zone and become surrounded by columnar epithelium during the process of healing. The ulcer is variable in size and shape. It is usually deep and is characteristically located at or below the level of the stricture. A "ring sign" of ulcer may be seen on the doublecontrast esophagram (Fig. 3). Healing of this chronic peptic ulcer produces scarring, with pseudodiverticular outpouching and eccentric narrowing of the lumen. Twelve patients in this series 

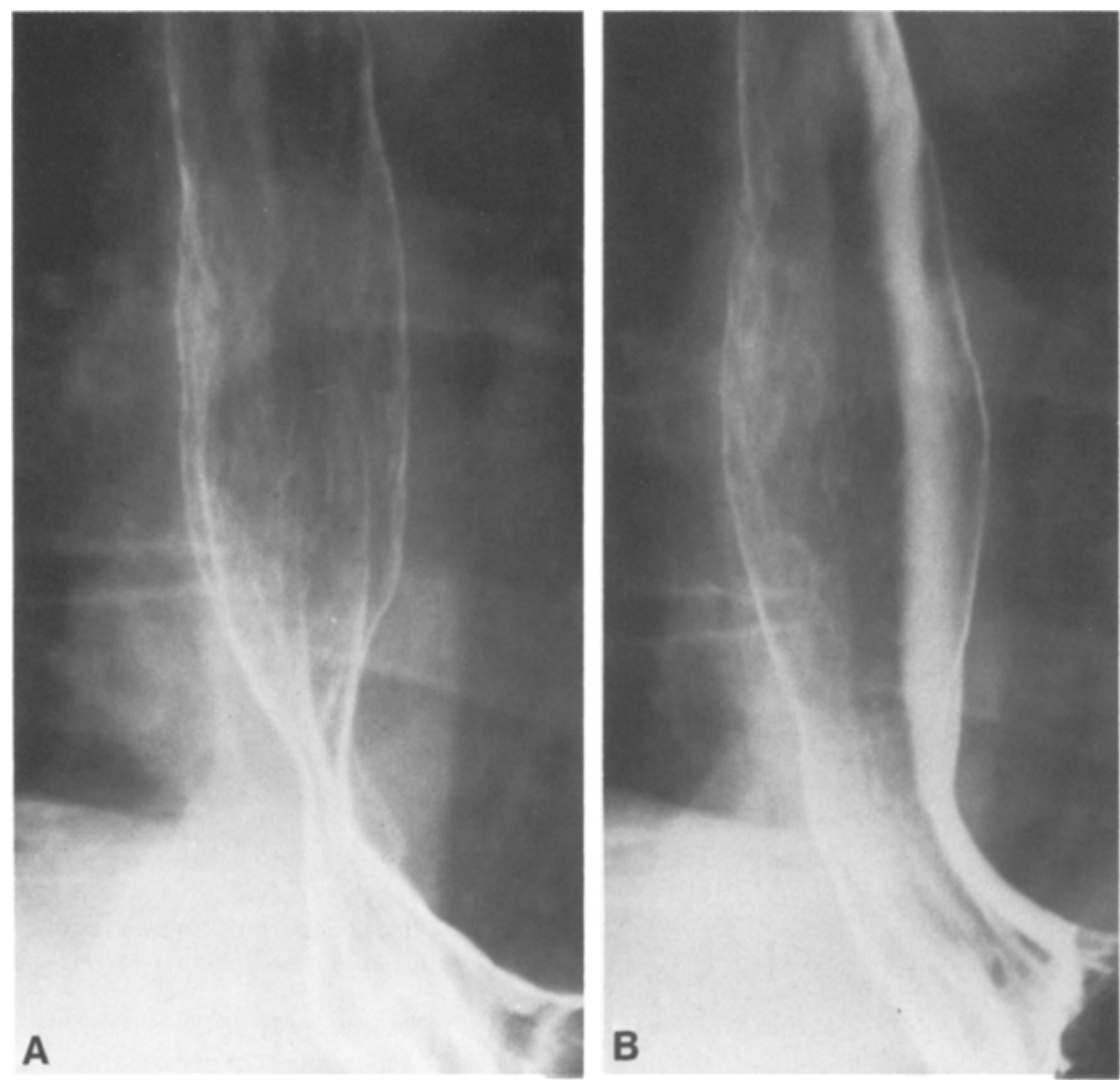

Fig. 2A, B. Double-contrast esophagograms show reticular pattern or areae gastricae appearance of mucosa in this patient with Barrett's esophagus. demonstrated Barrett's ulcers. Bremner emphasized that columnar lining develops as a protective response by the esophagus to the constant irritation of refluxed gastric contents and that peptic ulceration in Barrett's esophagus is due to an alkaline reflux or a mixture of acid pepsin and bile [19]. This hypothesis has not been confirmed by others. A recent case report indicates that other forms of severe injury to the esophageal mucosa, such as lye ingestion, can also result in the development of Barrett's epithelium [30].

\section{Cricopharyngeus Dysfunction and Zenker's Diverticulum}

Minor cricopharyngeal dysfunction occurs in patients with GER. Clinically these patients present with cervical dysphagia. We have found cricopharyngeal spasm or enlarged cricopharyngeus on radiologic study in patients with significant GER (Fig. 4). Smiley et al., based on radiologic studies showing hiatus hernia, suggested that GER produced upper esophageal sphincter (UES) dysfunction resulting in pharyngoesophageal diverticulum [31]. Some but not all patients with GER may have elevated UES pressure. It has been shown that UES pressure increases significantly over resting pressures in response to intraesophageal fluid infused distal to UES, to an intraluminal fluid bolus, or to intraesophageal balloon distention [32, 33]. This response of UES to recurrent or chronic episodes of GER may lead to cricopharyngeal dysfunction and hypertrophy (Fig. 5). Premature closure of UES has been suggested to play a role in the pathogenesis of Zenker's diverticulum. The pathophysiology of pharyngoesophageal diverticulum is usually assumed to be that "incoordination of cricopharyngeal motor function and abnormal relationship between pharyngeal contraction and UES contraction results in the formation of a pulsion diverticulum" [34].

However, a recent study using a low compliance pneumohydraulic infusion system found no pharyngeal incoordination in patients with Zenker's diverticulum and the UES resting pressures were actually lower than in the control group [35]. The formation of Zenker's diverticulum in our patient is most likely related to chronic increase in the intrapharyngeal pressure due to a combination of cricopharyngeal dysfunction and progressive Barrett's stricture. When a Zenker's diverticulum is discovered, the entire esophagus must 

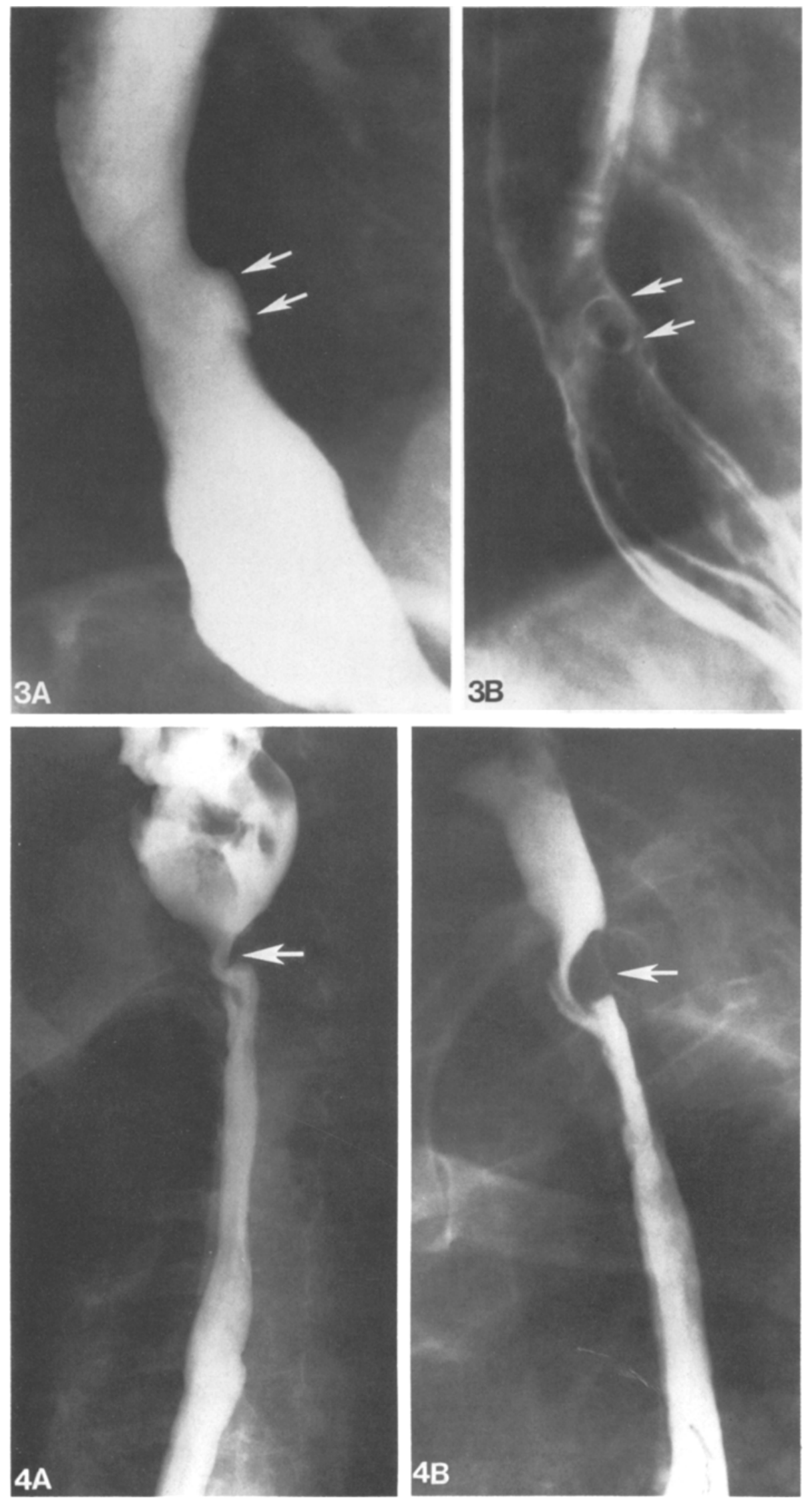

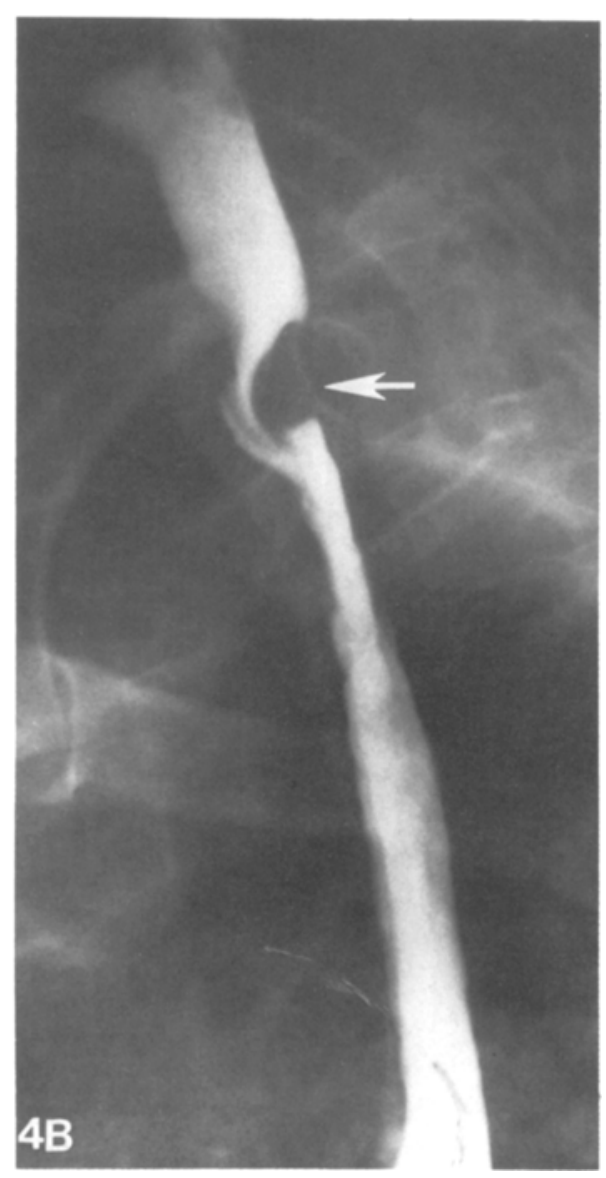

Fig. 3. A A single-contrast esophagogram shows an eccentric ulcer (arrows) with an associated stricture.

B Double-contrast view shows a classic "ring sign" of an ulcer (arrows).

Fig. 4. Cricopharyngeal dysfunction and Barrett's esophagus.

A, B Radiographs show markedly enlarged cricopharyngeus impression (arrow) with diffuse narrowing of the entire esophagus. The Barrett's mucosa involves the entire length of the esophagus and extends up to the level of the cricopharyngeus. 

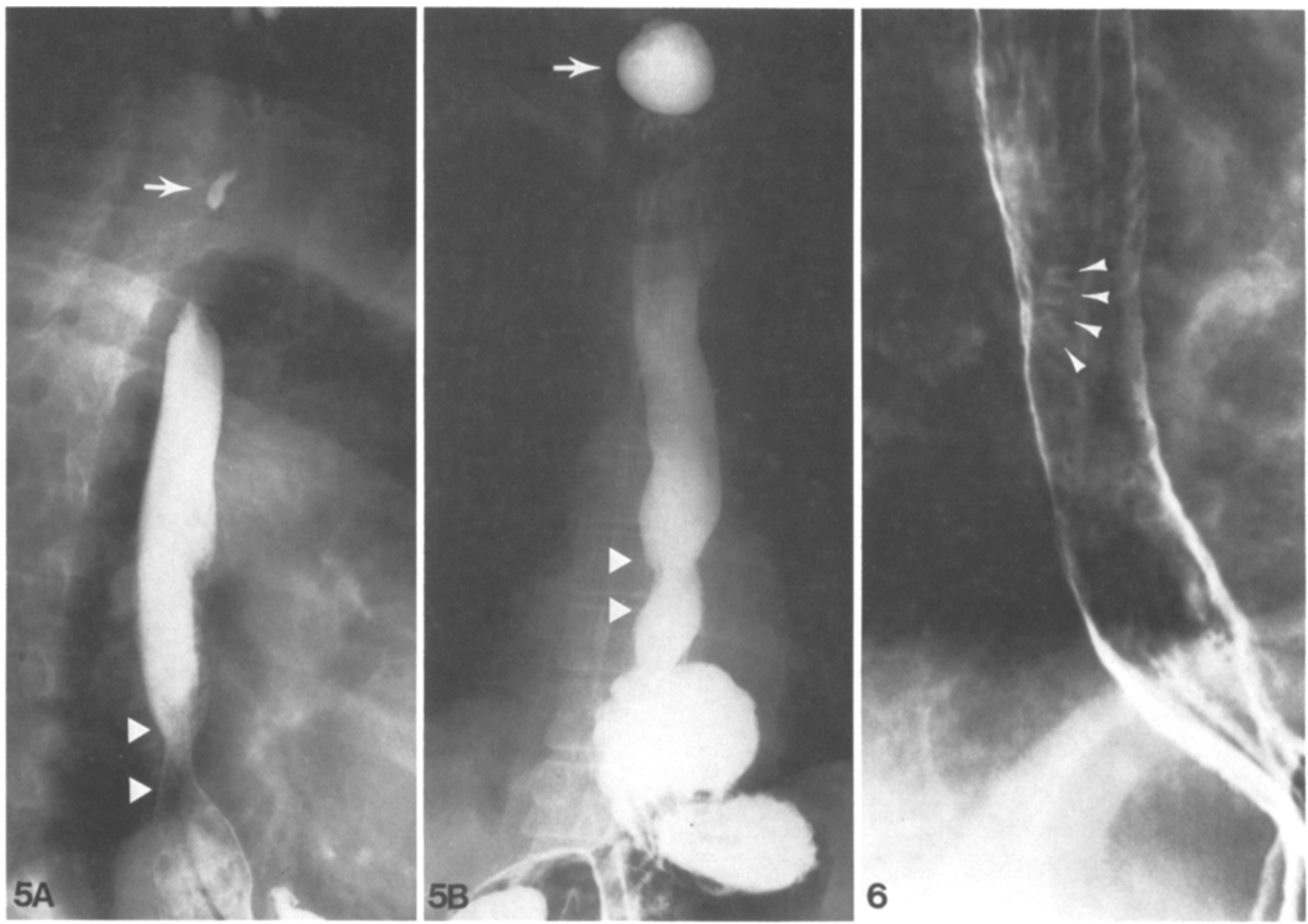

Fig. 5. Development of Zenker's diverticulum in association with Barrett's esophagus. A Examination in 1976 demonstrates a localized stricture (arrowheads) with dilated distal esophagus in this patient with GER and small Zenker's diverticulum (arrow). B Esophagram in 1980 shows marked enlargement of Zenker's diverticulum (arrow) due to progressive cricopharyngeal dysfunction despite radiographically stable Barrett's esophagus.

Fig. 6. A double-contrast esophagram shows fixed spiral folds radiating towards flattened right wall from a healed Barrett's ulcer (arrowheads).

be evaluated to rule out the presence of gastroesophageal reflux, distal stricture, or a hiatus hernia.

\section{Dilated Esophagus Distal to a Stricture}

This "sign of chronic gastroesophageal reflux" involves dilatation of esophagus below the level of the stricture. Som and Wolf [21] described three segments in Barrett's esophagus. The proximal segment consisted of normal esophagus, the middle segment below the level of the stricture/ulcer showed dilated esophagus, and the third segment consisted of globular appearance of a sliding hiatus hernia. In our experience dilated distal esophagus with or without associated hiatus hernia and wide open cardia is always associated with significant GER. The probable explanation for this finding is direct effect of GER on the esophagus causing atony and dysmotility. Although this sign of GER is well known in children [36], it has not been stressed adequately in adults. Dilated esophagus distal to a stricture was seen in 22 cases with significant spontaneous GER.

\section{Fixed Spiral Folds}

Transverse folds constitute a transient finding usually seen at double-contrast esophagography in $2-3 \%$ of patients with otherwise normal esophagus. These folds are seen with increasing frequency $(10-15 \%)$ in patients with GER. However, fixed transverse folds as described recently result from scarring due to longitudinal ulceration due to chronic reflux esophagitis [37]. In 3 of our patients with Barrett's esophagus fixed spiral folds were the 
only radiologic sign of Barrett's esophagus (Fig. 6). This is due to healing of a Barrett's ulcer which is usually deep and eccentrically located.

\section{Conclusion}

Review of 65 cases of pathologically proved Barrett's esophagus has revealed a wider spectrum of radiologic features than previously described. It is important for radiologists to be aware of these features, since the incidence of Barrett's esophagus is probably increasing. The exact prevalence of Barrett's esophagus is not known. The endoscopic reports suggest a range from $0.5 \%$ in general series to $11.5 \%$ in patients with symptomatic GER [38-40]. Although Barrett's mucosa has been noted to develop mostly in patients with hiatus hernia with GER, it has also been described in patients with scleroderma [41], in patients with achalasia after Heller's myotomy [42], and patients with Zollinger Ellison syndrome [43] and post-gastrectomy patients [44]. The present series also had a similar combination of cases. These features of Barrett's esophagus even in different clinical settings should alert radiologists, because Barrett's esophagus is considered a premalignant condition [45]. The reported frequency of adenocarcinoma in patients with Barrett's esophagus in larger series varied from 2 to $10 \%[13,39,40]$. These figures may be too high because of selection bias; however, the risk is certainly significant and needs to be determined more accurately.

Acknowledgment. I wish to thank Ms. Barbara Smith for excellent secretarial assistance in the preparation of the manuscript, and Gerald Abrams, M.D., Professor of Pathology, University of Michigan, for review of the pathological material for this study.

\section{References}

1. Barrett NR: Chronic peptic ulcer of the esophagus and esophagitis. Br J Surg 38:175-182, 1950

2. Barrett NR: The lower esophagus lined by columnar epithelium. Surgery 41:881-894, 1957

3. Allison PR, Johnstone AS: The esophagus lined with gastric mucous membrane. Thorax 8:87-101, 1953

4. Morris KN: Gastric mucosa within the esophagus. Aust NZ J Surg 25:24-30, 1955

5. Cohen BR, Wolf BS, Som M, Janowitz HD: Correlation of manometric, oesophagoscopic and radiological findings in the columnar-lined gullet (Barrett syndrome). Gut 4:406-412, 1963

6. Mossberg SM: The columnar lined oesophagus (Barrett syndrome); an acquired condition? Gastroenterology $50: 671-676,1966$

7. Adler RH: The lower esophagus lined by columnar epithelium; its association with hiatus hernia, ulcer, stricture and tumor. J Thorac Cardiovasc Surg 45:13-32, 1963

8. Burgess JN, Payne WS, Anderson HA, Weiland LH, Carl- son HC: Barrett's esophagus, the columnar epithelial lined lower esophagus. Mayo Clin Proc 46:728-734, 1971

9. Trier JS: Morphology of the epithelium of the distal esophagus in patients with mid esophageal peptic strictures. Gastroenterology 58:444-461, 1970

10. Abram L, Heath D: Lower esophagus lined with intestinal and gastric epithelia. Thorax 20:66-72, 1965

11. Bremner CG, Lynch VP, Ellis FH: Barrett's esophagus: congenital or acquired? An experimental study of esophageal mucosal regeneration in the dog. Surgery 68:209-216, 1970

12. Hamilton SR, Yardley JH: Regeneration of cardiac type mucosa and acquisition of Barrett's mucosa after esophagogastrectomy. Gastroenterology 72:669-675, 1977

13. Naef AP, Savary M, Ozello L: Columnar lined lower esophagus: an acquired lesion with malignant predisposition. $J$ Thorac Cardiovasc Surg 70:826-835, 1975

14. Goldman MC, Beckman RC: Barrett's syndrome: case report with discussion about concepts of pathogenesis. Gastroenterology $39: 104110,1960$

15. Vieux U, Dave P, Joseph Y: Barrett's esophagus; unusual features. Mt Sinai J Med (NY) 48:58-60, 1981

16. Mangla JC: Barrett's esophagus: an old entity rediscovered. $J$ Clin Gastroenterol 3:347-356, 1981

17. Messian RA, Hermos UA, Robbins AH, Friedlander DM, Schimmel EM: Barrett's esophagus; clinical review of 26 cases. Am J Gastroenterol 69:458-466, 1978

18. Stadelmann O, Elster K, Kuhn HA: Columnar lined oesophagus (Barrett's syndrome); congenital or acquired? Endoscopy 13:140-147, 1981

19. Bremner CG: The columnar lined (Barrett's) esophagus. In Nybus L (ed): Surgery Annual. New York: AppletonCentury-Crofts, 1977

20. Borrie J, Goldwater L: The columnar lined esophagus: assessment of etiology and treatment. A 22 year experience. $J$ Cardiovasc Thorac Surg 71:825-834, 1976

21. Som ML, Wolf BS: Peptic ulcer of the esophagus and esophagitis in gastric lined esophagus. JAMA 162:641-644, 1956

22. Wolf BS, Marshak RH, Som ML: Peptic esophagitis and peptic ulceration of the esophagus. AJR 79:741-759, 1958

23. Som ML, Shapiro JH, Jacobson HC: The "gastric lined" esophagus with esophagitis. Radiology 69:856-859, 1957

24. Missakian MM, Carlson HC, Anderson HA: The roentgenologic features of the columnar epithelial lined lower esophagus. AJR $99: 212-217,1967$

25. Robbins AH, Hermos JA, Schimmel EM, Friedlander DM, Messian RA: The columnar lined esophagus: analysis of 26 cases. Radiology 123:1-7, 1977

26. Robbins AH, Vincent ME, Saini M, Schimmel EM : Revised radiologic concepts of the Barrett's esophagus. Gastrointest Radiol 3:377-381, 1978

27. Levine MS, Kressel HY, Caroline DF, Laufer I, Herlinger $\mathrm{H}$, Thompson JJ: Barrett's esophagus: reticular pattern of the mucosa. Radiology 147:663-667, 1983

28. Paull A, Trier JS, Dalton MD: The histologic spectrum of Barrett's esophagus. $N$ Engl J Med $295: 476-480,1976$

29. Endo M, Kobayashi S, Kosu T, Kakemodo T, Nakayama $\mathrm{K}$ : A case of Barrett's epithelialization followed up for five years. Endoscopy 6:48-51, 1974

30. Spechler SJ, Schimmel EM, Dalton JW, Doos W, Trier JS: Barrett's epithelium complicating lye ingestion with sparing of the distal esophagus. Gastroenterology $81: 580-583,1981$

31. Smiley TB, Caves PK, Porter DC: Relationship between posterior pharyngeal pouch and hiatus hernia. Thorax $25: 725-731,1970$ 
32. Gerhardt DC, Shuck TJ, Bordeaux RA, Winship WH: Upper esophageal sphincter: response to volume, osmotic and acid stimuli. Gastroenterology 75:268-274, 1978

33. Gray JE, Lockard O, Shuck TJ, Winship DH: Response of the upper esophageal sphincter and upper esophageal intraluminal esophageal distension. Gastroenterology 76: A 1143, 1979

34. Ellis FH, Schlegel JF, Lynch VP, Payne WS: Cricopharyngeal myotomy for pharyngoesophageal diverticulum. Ann Surg 170:340-349, 1969

35. Knuff TE, Benjamin SB, Castell DO: Pharyngoesophageal (Zenker's) diverticulum: a reappraisal. Gastroenterology $82: 734-736,1982$

36. Swishchuk LE, Hayden CK, Van Caillie BD: Mega-aeroesophagus in children. A sign of gastroesophageal reflux. Radiology 141:73-76, 1981

37. Levine MS, Goldstein HM: Fixed transverse folds: a sign of reflux esophagitis. AJR 143:275-278, 1984

38. Trier JS, Curtis RL: Barrett's esophagus. In Sherlock $P$, Jerry Glass $G$ (eds): Progress in Gastroenterology. New York: Grune and Stratton, 1983, pp 231-250
39. Sjogren RW Jr, Johnson LF : Barrett's esophagus: a review. Am J Med 74:313-321, 1983

40. Bozymski EM, Herlihy KJ, Orlando RC: Barrett's esophagus. Ann Intern Med 97:103-107, 1982

41. Agha FP, Dabich L: Barrett's esophagus complicating scleroderma. Gastrointest Radiol 10:325-329, 1985

42. Feczko PJ, Chan KM, Halpert RD, Batra SK: Barrett's metaplasia and dysplasia in postmyotomy archalasia patients. Am J Gastroenterol 78:265-268, 1983

43. Agha FP: Esophageal involvement in Zollinger Ellison syndrome. AJR 145:721-725, 1985

44. Meyer W, Vollmer F, Bar W : Barrett's esophagus following total gastrectomy. A contribution to its genesis. Endoscopy 12:121-126, 1979

45. Barardi RS, Devaiah KA: Barrett's esophagus (collective review). Surg Gynecol Obstet 183:521-538, 1983

Received: November 1, 1984 ; accepted: January 8, 1985 